\title{
Pressupostos e subentendidos segundo a Teoria da Argumentação na Língua*
}

Cristiane Dall Cortivo Lebler ${ }^{a}$

\begin{abstract}
Resumo
Este trabalho tem como objetivo realizar um estudo diacrônico dos conceitos de pressuposição e de subentendido na Teoria da Argumentação na Língua (ANL). Desenvolvida, inicialmente, por Oswald Ducrot e Jean-Claude Anscombre e, mais recentemente, por Oswald Ducrot e Marion Carel, a ANL passou por reformulações que tiveram como objetivo mantê-la fiel ao seu pressuposto de base, de que a argumentação está inscrita na língua. Tais reformulações, como a exclusão de elementos pragmáticos e a não aceitação dos topoi como constitutivos do sentido, impactaram na explicação de alguns fenômenos linguísticos, dentre os quais situamos aqueles que ora analisamos. Para levar a cabo nosso objetivo, foram realizadas leituras de alguns textos teóricos que tratam do tema a fim de refazer o percurso que apresenta como os pressupostos e os subentendidos são entendidos em cada uma dessas fases.
\end{abstract}

Palavras-chave: Pressuposto. Subentendido. Sentido.

*Este artigo foi elaborado com base na tese de doutorado defendida pela autora com orientação de Leci Borges Barbisan (PUCRS) Recebido em 30 de novembro de 2015 Aceito em 05 de março de 2016

${ }^{a}$ Doutora em Linguística e Letras pela PUCRS e professora da Universidade de Santa Cruz do Sul, cristianedc@unisc.br 


\section{Introdução}

O estudo semântico da linguagem verbal tem como um dos marcos iniciais o texto de Frege intitulado Sobre o sentido e a referência, publicado originalmente em 1892. Desde então, filósofos, lógicos e linguistas discutem a questão que compreende, dentre outros aspectos, o estudo dos sentidos não ditos, como os pressupostos e os subentendidos. Autores como o próprio Frege, e, mais recentemente, Strawson (1950), Sellars (1954), Fillmore e Langendoen (1971), Ducrot (1977; 1987a; 1987b; 1987c; 1992), Carel e Ducrot (2008) e Carel (2011) dedicaram-se a esses elementos semânticos, que comportam conceitos e descrições bastante variadas.

É no quadro teórico destes últimos autores que se inscreve este trabalho. Com a finalidade de discutir as modificações pelas quais passaram essas noções, apresentamos uma investigação diacrônica a respeito dos conceitos de pressuposição e de subentendido no quadro da Semântica Argumentativa, desenvolvida inicialmente por Oswald Ducrot e Jean-Claude Anscombre e, nos últimos anos, por Oswald Ducrot em parceria com Marion Carel.

A pressuposição e o subentendido foram objeto de questionamento por parte do autor em diversas fases do desenvolvimento dos seus estudos acerca da linguagem. Seu primeiro trabalho a respeito da pressuposição, por exemplo, foi publicado em 1966, na revista Études de Linguistique Appliquée, com o título Le roi de France est sage: implication logique et présupposition linguistique. Depois desse, outros se seguiram, especialmente a obra Princípios de semântica linguística: dizer e não dizer (1977), bem como artigos e capítulos de livros - analisados na sequência deste trabalho - nos quais a análise do tema, recentemente desenvolvida com Carel, ainda não se esgotou.

Para Ducrot (1987b, p. 14), a descrição semântica de uma língua $\mathrm{L}$ consiste em "um conjunto de conhecimentos que permitem prever, frente a um enunciado [frase] A de L, produzido em circunstâncias $X$, o sentido que esta ocorrência de A tomou neste contexto". Para colocar em prática tal programa, o autor parte de um esquema embasado em uma hipótese segundo a qual o conjunto de conhecimentos mobilizado para compreender tal ocorrência diz respeito a dois componentes de natureza distinta: o componente linguístico, que consiste no 
${ }^{1} \mathrm{O}$ que nos autoriza a tomar o componente linguístico como sinônimo da significação é a seguinte passagem de Ducrot (1987b, p. 16 e 17): “É possível atribuir ao componente linguístico uma postura relativamente sistemática, aî integrando um pequeno número de regras gerais suscetíveis de interferir e de combinar seus efeitos de acordo com relações previsíveis". conjunto de conhecimentos linguísticos da língua L e que atribui a cada frase, independente do contexto, determinada significação; e o componente retórico, que seria o responsável por precisar a significação efetiva de A na circunstância X.

A distinção desses dois níveis opera um papel fundamental na primeira descrição realizada a respeito dos pressupostos e dos subentendidos. O componente linguístico constitui-se de uma série de regras sistemáticas que, em momentos posteriores do desenvolvimento teórico, foram denominadas significação ${ }^{1}$, sendo a existência dessas regras intermediada pelas frases. A significação das frases, descrita por Ducrot (1987b), é composta por instruções, que são o resultado ao qual o linguista chega após a análise de inúmeras ocorrências de uma frase, A, por exemplo, em circunstâncias diferentes, X, Y e Z. Assim, o sentido de um enunciado não seria a soma da significação mais a enunciação, que conteria os traços situacionais, mas se trataria de uma transformação da língua em discurso pela ação de um locutor, que tem seus limites de sentido especificados pelo acontecimento enunciativo.

Os caminhos traçados por Ducrot (1977), inicialmente, diferenciavam os dois fenômenos, pressuposto e subentendido, pela sua origem: o primeiro estaria ligado àquilo que ele chamava componente linguístico, que entendemos como o construto teórico língua, ou seja, o pressuposto estaria presente desde um estrato mais fundamental que o uso da língua. Já o segundo, contrariamente, somente se revelaria na enunciação, como um efeito, na terminologia do autor, a partir do componente retórico.

Para Ducrot (1977), a descoberta dos pressupostos e subentendidos na linguagem deve-se a uma mudança de ponto de vista a respeito do seu caráter: viam-se como funções fundamentais da linguagem a comunicação e a transmissão de informações. A mudança do paradigma informativo para aquele que vê a linguagem como o motor das relações intersubjetivas abriu novas possibilidades de estudo e fez emergir problemas para os quais era necessário buscar uma explicação: um desses problemas é justamente o fato de que nem todos os conteúdos comunicados são explícitos.

A necessidade de implicitação dos conteúdos deve-se a diferentes razões, apontadas por Ducrot (1977) como a existência de determinados tabus linguísticos (há temas ou 
palavras sobre os quais não é permitido fazer menção explícita); a restrição quanto àquilo que o locutor tem autorização para falar; ou, ainda, a autoridade exercida ou não pelo locutor (há determinados tipos de relação intersubjetiva nos quais o locutor não tem autorização para tratar de determinados assuntos ou colocar o interlocutor em uma dada situação jurídica - dar-lhe uma ordem, fazer-lhe um pedido ou sugerirlhe um comportamento).

Nesse sentido, as palavras de Ducrot (1977, p. 09) “a língua não se realiza senão quando fornece um lugar de encontro para os indivíduos" dão o tom da descrição linguística: por um lado, leva em conta a interação dos indivíduos por meio da linguagem, e, por outro, reconhece na linguagem a capacidade de produzir essa interação. Por isso, tanto o pressuposto quanto o subentendido, segundo a visão do autor, são descritos a partir das relações enunciativas propiciadas pela linguagem, num primeiro momento situando o pressuposto no nível da significação - componente linguístico - e o subentendido no plano da enunciação - componente retórico.

Além do componente retórico e do componente linguístico, outros dois conceitos são introduzidos para a explicação dos implícitos: a significação literal (SL) e a significação implícita (SI), sendo aquela o dispositivo que aciona esta. A SL é definida em Ducrot (1992) como significação, presente em cada frase da língua. Quanto à SI, a entendemos como o sentido que o locutor pretende derivar de seu enunciado, ou seja, o próprio implícito. Para o autor, a significação implícita só pode ser descoberta uma vez tendo sido compreendida a significação literal, podendo ocorrer o contrário também - o interlocutor só decifra a significação literal, permanecendo num nível mais superficial de entendimento do enunciado.

Vejamos, a seguir, como cada um dos conceitos foi construído e reconceituado pelo autor.

\section{Os pressupostos}

Ao longo do desenvolvimento teórico da ANL, a pressuposição foi um dos conceitos que mais sofreu reformulações. Os primeiros textos de Ducrot, publicados nos anos 1960, já tratavam do fenômeno, tendo o autor lhe dedicado uma obra inteira - Princípios de semântica linguística: dizer e não 
dizer, tradução publicada no Brasil em 1977 e originalmente publicada na França sob o título Dire et ne pas dire: principes de sémantique linguistique no ano de 1972.

Seu constante interesse pela pressuposição parece estar motivado pela relação que estabelece com outros fenômenos da linguagem, como a polifonia, a negação, a interrogação e o encadeamento, estes três últimos considerados os critérios para a descoberta dos pressupostos. Tendo em vista esse constante movimento teórico, seguiremos a linha cronológica dos trabalhos que abordam os pressupostos, quais sejam: Ducrot (1977; 1987a; 1987b; 1987c; 1992); Carel e Ducrot (2008) e Carel (2011).

Na obra Princípios de Semântica Linguística (1977), Ducrot afirma que os implícitos fundados no enunciado, ou seja, aqueles inscritos no componente linguístico, são decorrentes da organização interna do discurso, pela qual a proposição implícita é decorrente de alguma lacuna deixada no encadeamento das proposições explícitas. Podemos usar esse procedimento para dar a entender algo que não queremos expressar abertamente, como no exemplo (1) Encontrei Pedro na PUCRS, ele estava preocupado, referindo-nos: (a) às dificuldades pelas quais Pedro está passando; (b) à ida do locutor à Universidade. Já o exemplo (2) Pedro gosta de carros importados pode ser usado para dar a conhecer o pouco apreço que Pedro tem por carros nacionais.

Os procedimentos de implicitação usados em (1) e em (2) são diferentes: em (1), o segmento implícito que é expresso por (a) poderia ser encadeado ao enunciado através de logo, resultando em (1') Encontrei Pedro na PUCRS, ele estava preocupado, logo, deve estar com algum problema; e (1") Pedro esteve na universidade apresenta um conteúdo pressuposto que aparece implicitado em (1), ao qual nos referimos em (b). Já em (2), pela adjetivação, o locutor exclui os carros nacionais e os coloca como não pertencentes ao conjunto dos carros pelos quais Pedro tem preferência, o que está representado em $\left(2^{\prime}\right)$ Pedro gosta pouco (ou menos) de carros nacionais. Tal análise está sustentada pela lei da economia (DUCROT, 1977), segundo a qual o interlocutor tende a supor que são úteis todas as informações que o locutor disponibiliza em seu enunciado.

Outro exemplo, desta vez um exemplo clássico de pressuposição, aparece em (3) Pedro parou de fumar, sobre o qual Ducrot desenvolve boa parte de seu estudo sobre esse 
tema. Neste caso, o posto, que é expresso abertamente pelo enunciado, é a condição de Pedro como ex-fumante, expressa por (3a) Pedro não fuma atualmente; já o pressuposto é o conteúdo evocado e expresso em (3b) Pedro fumava.

Os pressupostos, implícitos marcados desde o componente linguístico, estão circunscritos àquilo que o autor denomina sentido literal, ou, mais precisamente, estão marcados na significação das palavras ou frases da língua. Por isso, pertencem ao domínio comum dos dois personagens do diálogo, locutor e alocutário que, falantes da mesma língua e detentores desse conhecimento, não podem deixar de aceitar sua presença.

Apresentado, portanto, como pertencente ao "nós", o pressuposto parece situar-se como num passado do conhecimento comum aos dois personagens do diálogo, ao qual o locutor parece fazer alusão em sua fala. Já o posto é reivindicado pelo "eu" e simultâneo ao ato da comunicação, apresentado quando da enunciação da frase que o implica. Por ser um fato de língua, a pressuposição não está ligada a nenhuma reflexão individual e não pode ser justificada ou explicada por raciocínio, apresentando-se como uma contribuição do próprio enunciado. Além disso, a ligação da pressuposição com os fenômenos sintáticos da negação e da interrogação, que constituem critérios para revelar sua presença, parece ser um motivo adicional que atesta sua inscrição na significação, ou seja, na língua (DUCROT, 1987b).

Daremos um exemplo de como as transformações sintáticas operadas pela negação e pela interrogação atuam sobre um enunciado, mantendo-lhe os pressupostos. Tomemos o enunciado (4) Pedro trabalhou pouco na última semana. É possível perceber que o pressuposto (4') Pedro trabalhou se mantém mesmo com a transformação da asserção em interrogação, como em (4b) É verdadeiro que Pedro trabalhou pouco na última semana?, ou fazendo agir sobre ela a negação, como em (4a) $E$ falso que Pedro trabalhou pouco na última semana.

O terceiro critério aplicado para a demonstração dos pressupostos é o critério do encadeamento (ou subordinação). A subordinação de um segmento a um enunciado com pressupostos se dá sempre ao conteúdo posto e nunca ao conteúdo pressuposto: é o caso de (4c) Pedro trabalhou pouco na última semana embora os prazos estivessem vencendo, que afirma a 
escassa quantidade de trabalho e a relaciona com a urgência dos prazos, mantendo o pressuposto (4') Pedro trabalhou. No entanto, se a subordinação tivesse sido encadeada ao pressuposto, a orientação argumentativa dada por ele seria completamente outra, bem como o sentido resultante seria considerado até mesmo pouco aceitável, expresso em $(4 \mathrm{~d})^{*}$ Pedro trabalhou pouco na última semana por isso conseguiu vencer os prazos pendentes.

Essa primeira abordagem dos pressupostos e dos subentendidos é reexaminada no posfácio publicado na obra de Paul Henry, intitulada La mauvaise outil (França, 1977; Brasil, 1992), e no segundo capítulo da obra Le dire et le dit (França, 1984; Brasil,1987). A tese que Ducrot pretende rever é a ideia de que os pressupostos estariam unicamente determinados pela significação das frases, ou o que ele chama de concepção antiga da pressuposição, cuja máxima afirmava que os pressupostos se realizavam apenas da significação da frase para o sentido do enunciado. Ducrot (1987c) mantém, com ressalvas, um princípio secundário, de que a significação da frase poderia implicar a existência deste ou daquele pressuposto quando da sua realização no enunciado.

Para iniciar o reexame de tal tese, Ducrot (1987c) apresenta três tipos de considerações, que justificariam a atribuição do pressuposto às frases da língua, às quais se opõe. A primeira delas apoia-se na descrição dos pressupostos como condição de emprego: de acordo com a literatura filosófica sobre o assunto, se o pressuposto $P$ encontra-se marcado na frase $F$, e se na ocorrência $O$ de $F$ o pressuposto $P$ não estiver presente, a ocorrência $O$ pode ser tida como um emprego estranho, anômalo, e tal afirmação (da pertinência do pressuposto à frase) seria tida como falsa. Por isso, torna-se evidente, segundo a literatura filosófica, que as condições de emprego não podem caracterizar o enunciado, apenas a frase, pois o enunciado, ele mesmo, já é um emprego. Sendo o pressuposto uma condição de emprego, ele só poderia encontrar sua origem na significação.

A segunda justificativa para inserir os pressupostos na frase toca em questões delicadas e em fatos incontestáveis para a descrição da pressuposição. Para Ducrot (1987c), é preciso definir sobre qual estrato incidem a negação e a interrogação: sobre a frase, construto teórico, ou sobre o enunciado, realização da frase? Para o autor, elas incidem sobre a frase, pois não faz sentido atribuir transformações sintáticas ao enunciado que já 
é, ele próprio, resultado de uma enunciação que teve por fim interrogar, negar ou afirmar; essas transformações só podem afetar a frase, transformando-a em um enunciado interrogativo ou negativo, sob os quais seriam mantidos os pressupostos.

A terceira justificativa para a inscrição dos pressupostos no componente linguístico nasce da definição da pressuposição como um ato de fala. Ducrot (1977) assinalava a pertinência dos atos ilocutórios à frase por oposição aos atos perlocutórios, os quais seriam decorrentes do enunciado, como um efeito indireto da enunciação. O que fez com que Ducrot (1977) inserisse os atos ilocutórios na frase foi um deslize conceitual, que partia da eficácia do ato ilocutório, enquanto fala, para a ideia de que ele seria sustentado por uma eficácia inerente às próprias palavras da língua. Sendo a pressuposição um ato ilocutório, e este estando inscrito na frase, consequentemente havia mais um motivo para crer que a pressuposição seria transmitida da frase para o enunciado.

Essas três justificativas são discutidas pelo autor, pois são elas que motivam a revisão da tese acima exposta. A primeira delas, que caracteriza a pressuposição como condição de emprego, é rejeitada pelo autor, que defende uma posição contrária àquela da literatura filosófica.

Em relação à segunda justificativa, que insere a pressuposição na frase em razão das transformações sintáticas não poderem afetar senão a frase, Ducrot (1987c) não a rejeita, mas restringe sua aplicabilidade: admite a interrogação e a negação como critérios que podem diferenciar quais são os pressupostos marcados na frase em oposição àqueles que se situam no enunciado, e coloca como critério principal de revelação dos pressupostos o encadeamento. Ao admitir que o encadeamento é o método mais eficaz para a descoberta dos pressupostos, o autor afirma também que estes não orientam para a continuação do discurso, ficando essa orientação a cargo do posto (conforme exemplos $(4 \mathrm{c})$ e $\left.(4 \mathrm{~d})^{*}\right)$.

A terceira justificativa para inscrever a pressuposição no nível da frase é rebatida pela análise de enunciados capazes de revelar que o pressuposto pode aparecer como resultado de subentendidos (os subentendidos, para Ducrot, são efeitos secundários da enunciação, estão implicados de modo indireto e precisam ser descobertos pelo interlocutor, conforme veremos a seguir). Para fins de ilustração, voltemos ao exemplo (4) Pedro 
trabalhou pouco na última semana. Desse exemplo, podem ser compreendidos os subentendidos (4e) O trabalho é garantia de sucesso profissional e (4f) Pedro não terá sucesso profissional.

O subentendido (4f) é necessário para garantir o surgimento do subentendido (4e). Supondo que o objetivo do locutor ao enunciar (4) seja chamar a atenção de Pedro pela sua pouca produtividade, o subentendido encarregado de fazê-lo é aquele contido em (4e), sendo que (4f) funciona, neste caso, como um pressuposto: Se o sucesso profissional é garantido pelo trabalho e Pedro trabalhou pouco, Pedro não terá sucesso profissional. Para o autor:

é necessário, então, fazer admitir que [a pressuposição] pode aparecer ao nível mesmo do enunciado e até mesmo sob a forma de subentendido. Haveria pressuposições subentendidas, como há pedidos subentendidos. (DUCROT, 1987c, p. 37) ${ }^{2}$

A conclusão apontada pelo teórico é que existem pressupostos marcados na frase - evidenciados pelos critérios clássicos -; há pressupostos que são revelados pelo critério do encadeamento, mas que não resistiriam à ação das transformações sintáticas; e há pressupostos que surgem apenas a partir do enunciado, como apontamos com os exemplos (4e) e (4f). No entanto, o teórico mantém a pressuposição como um elemento do sentido, caracterizada por obrigar o destinatário a admiti-la sem, contudo, dar-lhe o direito de prosseguir o diálogo a partir dela.

Que ela [a pressuposição] possa ser marcada a partir do nível da frase confirma, então, no que tange à língua, no sentido mais tradicional do termo, a ideia de que a utilização polêmica da linguagem não se acrescenta à língua - em virtude de alguma lei de discurso ligada à natureza humana. (...) A língua é consagrada à interação dos indivíduos. (DUCROT, 1987c, p. 41).

${ }^{2}$ Os pedidos subentendidos aos quais o autor faz alusão são exemplificados pelo enunciado Você é capaz de fechar a janela?, cuja finalidade não é perguntar ao alocutário sobre a sua capacidade de fechar a janela, mas de subentender o pedido de fechá-la.
Assim, a definição que o autor propõe para a pressuposição é exposta nos seguintes termos "as indicações que um enunciado traz, mas sobre as quais o locutor não faz recair a continuidade do seu discurso" (DUCROT, 1987c, p. 38), revelando a existência de pressupostos que os critérios usados pelas teorias clássicas deixariam passar despercebidos.

Alguns anos mais tarde, Ducrot (1987a), ao dar corpo à sua teoria sobre a polifonia, apresenta uma nova explicação 
para o desmembramento de posto e pressuposto em dois conteúdos independentes. A teoria da polifonia estabelece que o locutor nunca se expressa diretamente, mas coloca em cena certos personagens, que ele denomina enunciadores, com os quais o locutor se relaciona e que são responsáveis por pontos de vista. Dessa forma, o autor se opõe à caracterização da pressuposição proposta em seu livro Princípios de Semântica Linguística (1977) no qual propunha, para um enunciado com pressupostos, a realização de dois atos ilocucionais: um de asserção e outro de pressuposição.

Na nova visão apresentada pelo viés polifônico, os conteúdos posto e pressuposto aparecem desmembrados e sob responsabilidade de dois enunciadores distintos - E1 e E2. E2, a quem é atribuído o conteúdo expresso pelo posto, é assimilado a L, o que permite considerá-lo como um ato de afirmação - já que é o conteúdo assumido por ele. Já o conteúdo pressuposto é de responsabilidade de E1 e assimilado a um $\mathrm{SE}$, uma voz coletiva na qual L estaria localizado -, por isso dá sua concordância a esse enunciador. Portanto, no nível dos enunciadores, não há pressuposição, apenas dois conteúdos, ficando a cargo do enunciado a revelação dos pressupostos, conforme abaixo:

(4) Pedro trabalhou pouco na última semana.

E1 - Pedro trabalhou.

E2 - A quantidade de trabalho realizado por Pedro na última semana é escassa.

A pressuposição é marcada, então, não como o objeto de asserção do locutor, mas como uma informação presente em seu enunciado, e embora $\mathrm{L}$ a apresente como um elemento do sentido, não pretende assumir a responsabilidade por ela, o que impede, portanto, de encadear a sequência do seu discurso (ou permitir ao alocutário que o faça) a partir dos pressupostos.

Com o surgimento da Teoria dos Blocos Semânticos (TBS), pela tese de doutorado de Marion Carel (1992), muitos aspectos da ANL foram revistos e, com a criação de novas ferramentas, vários fenômenos já estudados foram submetidos aos novos conceitos e receberam uma descrição e uma explicação alinhada com o novo espírito dos estudos da Semântica Argumentativa. Dentre eles, estão a polifonia e, consequentemente, a pressuposição, considerada até o momento 
como um exemplo de discurso polifônico. Carel e Ducrot (2008) apresentam uma revisão e uma posição radical com relação aos conteúdos pressupostos e à polifonia, pois colocam em dúvida a pressuposição ou limitam de modo contundente sua extensão (CAREL; DUCROT, 2008, p. 12). Os três tipos de pressuposição que os autores analisam no trabalho acima mencionado são os apresentados em Princípios de semântica linguística: dizer e não dizer (1977), os quais relatamos a seguir:

a) Descrições definidas: exemplificado por (4) Pedro trabalhou pouco na última semana - pressupõe que Pedro trabalhou e põe a sua escassa quantidade de trabalho;

b) Factitivas: exemplificado por (5) Pedro sabe que $p$ pressupõe a verdade de " $\mathrm{p}$ " e põe a crença que Pedro tem em " $\mathrm{p}$ ";

c) Continuação ou cessação de estado: exemplificado por (3) Pedro parou de fumar - pressupõe que Pedro fumava antes e põe que Pedro não fuma mais.

Para Carel e Ducrot (2008), apenas o enunciado (4), representativo das descrições definidas, é tido como pressuposicional. O que levou os autores a realizarem essa revisão foi a crítica sofrida por Ducrot pelo fato de desmembrar o sentido do enunciado em dois conteúdos independentes, o posto e o pressuposto, demonstrando um desconhecimento em relação à unidade semântica expressa pelos enunciados.

A motivação para tal desmembramento vinha das indicações que as transformações sintáticas operavam no enunciado, invertendo o posto e deixando o pressuposto intacto (conforme exemplificamos anteriormente (4), (4a) e (4b)). A teoria polifônica standard tomava esses dois conteúdos como pontos de vista sob a responsabilidade de dois enunciadores distintos (DUCROT, 1987b), frente aos quais o locutor tomava as atitudes de concordar e assumir (exemplo (4) com E1 e E2). A respeito da crítica sofrida, Carel e Ducrot comentam:

fazemos nossa a crítica do desmembramento se ele significa que os conteúdos posto e pressuposto não têm sentido independentemente um do outro, de modo que se altera sua natureza ao atribuir-lhes enunciados separados. (CAREL; DUCROT, 2008, p. 12)

A proposta que vem em lugar da posição rejeitada pelos autores faz uso de conceitos da Teoria dos Blocos Semânticos, como o encadeamento argumentativo e a interdependência semântica. Os encadeamentos argumentativos são constituídos 
${ }^{3}$ As siglas PT e DC são abreviações das palavras francesas pourtant e donc, que significam, respectivamente, no entanto e portanto.

${ }^{4} \mathrm{~A}$ esse respeito, ver CAREL, Marion; DUCROT, Oswald. La semántica argumentativa: una introducción a la Teoría de los Bloques Semánticos. Buenos Aires: Colihue, 2005. por segmentos de discurso relacionados por conectores de dois tipos: transgressivos - no entanto $(P T)$ - e normativos portanto $(D C)^{3}$ - que, ao relacionar em um só encadeamento o posto e o pressuposto, conseguem manter a unidade de pensamento que o enunciado expressa. Para isso, posto e pressuposto são colocados em relação argumentativa: o que constituía o pressuposto passa a ser o suporte (primeiro segmento do encadeamento), e o posto, o aporte (segundo segmento do encadeamento).

Para as pressuposições do tipo factitiva, como o enunciado (5), a proposta de encadeamento é dada como (5a) péverdadeiro $D C$ Pedro pensa que $p$, no qual os segmentos têm seu sentido definido pela relação estabelecida entre si e expressa pelo conector, o que os autores denominam interdependência semântica, que revela um único sentido, uma forma particular de pensamento, aquela fundada no caráter verdadeiro de " $p$ ".

Para o tipo de pressuposição continuativa ou cessativa, demonstrada pelo exemplo (3), o encadeamento que melhor a representa é (3c) ter fumado PT não fumar. Posto e pressuposto, unidos num único encadeamento, expressam o sentido de modo mais próximo à realidade do enunciado. Não se trata de dizer que esse estado se produzia no passado e que não se produz atualmente, mas de uma mudança entre a realidade passada e a realidade presente, segundo a qual o comportamento atual é uma transgressão (no sentido linguístico do termo) em relação ao comportamento anterior.

Quanto à manutenção dos pressupostos sob a negação (incluindo na negação a interrogação, considerada como uma forma fraca de negação), sua explicação via TBS se dá pela lei da negação, segundo a qual um enunciado negado se transforma em converso ${ }^{4}$ do seu correspondente positivo. No caso do enunciado (3), o encadeamento que o representa teoricamente é (3c) ter fumado PT não fumar. O enunciado negativo correspondente a (3) é ( $\left.3^{\prime}\right)$ Pedro não parou de fumar, cujo aspecto que o representa é ( 3 'a) ter fumado DC fumar.

Temos, portanto, a manutenção do pressuposto no primeiro segmento (ter fumado) e a negação do posto (Pedro ainda fuma) no segundo segmento. A negação dos pressupostos se dá, como na descrição habitual, pela negação dita metalinguística, conforme o exemplo ( $\left.3^{\prime \prime}\right)$ Pedro não continua 
a fumar, ele sequer começou, cujo aspecto se materializa em (3"a) neg ter fumado DC neg fumar.

A colocação de posto e pressuposto em relação argumentativa expressa pelo conector elimina o desmembramento do sentido do enunciado em dois conteúdos independentes. Sendo o sentido expresso apenas por um encadeamento argumentativo, os autores eliminaram também o caráter polifônico atribuído aos pressupostos em Ducrot (1987a) para os tipos de pressuposição factitiva e continuativa ou cessativa. Para o primeiro tipo, aquele das descrições definidas, no entanto, seguem admitindo a descrição polifônica e pressuposicional habitual, pois não veem motivo para ligar argumentativamente os dois conteúdos. Assim, para o enunciado (4) Pedro trabalhou pouco na última semana, permanece o desmembramento do conteúdo em E1- a quantidade de trabalho executada por Pedro foi escassa, assumido pelo locutor, e em E2 Pedro trabalhou, ao qual o locutor dá a sua concordância.

Em 2011, Marion Carel dá continuidade à revisão sobre a pressuposição iniciada em Carel e Ducrot (2008), também questionando seu potencial polifônico. Para ela, a palavra polifonia tem dois tipos de definição: a primeira delas, encontrada em Ducrot (1987a), é denominada pela autora como polifonia semântica e definida como a alusão, por um único enunciado, a vários conteúdos. A segunda definição, ligada a Bakhtin e denominada polifonia intertextual, descreve a presença de várias instâncias enunciativas no interior da enunciação de um enunciado. $O$ ponto em comum entre elas é que ambas são declaradas.

Nesse cenário, a pressuposição é tida como um exemplo de polifonia semântica, à qual Carel atribui o exemplo (6) Pedro parou de dormir. O enunciado comunicaria de uma só vez que Pedro dormia antes (conteúdo pressuposto, que se mantém pela transformação da asserção em interrogação Pedro parou de dormir?) e que Pedro não dorme mais, conteúdo comunicado pelo locutor e objeto de sua asserção, posto pelo enunciado (conteúdo modificado pela interrogação ou negação).

Quanto ao segundo tipo de polifonia, a intertextual e atribuída a Bakhtin, o exemplo que trazemos para ilustrá-la é (7), um trecho do poema Canto de regresso à pátria, de Oswald de Andrade, que faz alusão à Canção do Exílio, de Gonçalves Dias (7'): 
(7) Minha terra tem palmares

Onde gorjeia o mar

Os passarinhos daqui

Não cantam como os de lá.

(Oswald de Andrade, Canto de regresso à pátria).

(7') Minha terra tem palmeiras

Onde canta o sabiá,

As aves que aqui gorjeiam

Não gorjeiam como lá.

(Gonçalves Dias, Canção do exílio).

A polifonia intertextual partilha da característica da pressuposição de não poder jamais ser negada: o locutor de (7) não pode negar a alusão que faz ao conteúdo de $\left(7^{\prime}\right)$. No entanto, esses dois tipos de polifonia se distinguem por dois motivos: pela forma de evocar os conteúdos associados aos enunciados e pela posição que o locutor assume diante desses conteúdos. Na polifonia semântica, o conteúdo pressuposto está inscrito na significação, e o locutor toma posições diante desses conteúdos - assume o conteúdo posto e concorda com o conteúdo pressuposto. Já na polifonia intertextual, a alusão ao conteúdo evocado não decorre de uma marca da significação, mas do enunciado, da sua combinação léxica. Além disso, o locutor não toma posição frente aos conteúdos evocados, ele apenas se posiciona em relação ao produto da sua própria enunciação.

Face aos dois acontecimentos polifônicos, Carel (2011) se interessa pelo primeiro, atribuído a Ducrot (1987a), e analisa especialmente sua relação com a pressuposição. Sua proposta segue a hipótese de Carel e Ducrot (2008), segundo a qual a pressuposição não pode ser caracterizada como uma fonte de polifonia. A justificativa para essa afirmação deve-se ao fato de posto e pressuposto aparecerem ligados por uma relação argumentativa, expressa por conectores do tipo portanto e no entanto.

O que o enunciado (6) Pedro parou de dormir comunica, portanto, não é a existência de dois estados (Pedro dormiu e Pedro não dorme mais), mas uma passagem de um estado para outro estar-acordado-apesar-do-seu-precedente-estado-desono (CAREL, 2011). Já a negação do enunciado (6) comunica 
outro predicado argumentativo, o qual é resultado de uma transformação: (6') Pedro não parou de dormir comunica um sentido consecutivo ele-dorme-porque-dormia-antes. Esses dois predicados, contidos nos grupos verbais parou de dormir e não parou de dormir, são expressões linguísticas que têm por significação ser $Q$ ainda que $P$ ou ser $Q$ pois $P$ (CAREL, 2011).

Como afirmado em Carel e Ducrot (2008), Carel (2011) reconhece que a pressuposição do tipo existencial (ou descrições definidas) constitui uma fonte de polifonia, pois não há razões para ligar argumentativamente os conteúdos posto e pressuposto em um único encadeamento. Não há laço argumentativo entre os conteúdos expressos por (4) Pedro trabalhou e a quantidade de trabalho realizada por Pedro foi escassa; para essa classe de enunciados, portanto, Carel mantém a descrição polifônica usual.

\section{Os subentendidos}

De menor interesse para Ducrot e, mais recentemente, para Ducrot e Carel, os subentendidos aparecem normalmente em seus artigos como exemplos daquilo que não são pressupostos. Por isso, os autores não se dedicaram ao estudo propriamente do subentendido, mas descreveram-no e explicaram-no por oposição à pressuposição. Nossa apresentação dos estudos a respeito do subentendido seguirá o método adotado para os pressupostos, respeitando a ordem de publicação dos trabalhos nos quais há a menção sobre o tema, quais sejam, Ducrot (1987b; 1987c) e Carel (2011).

Em (1987b), Ducrot faz uma descrição inicial dos pressupostos e subentendidos, caracterizando-os a partir do comportamento semântico de alguns enunciados com relação aos conteúdos evocados. Sua principal hipótese é de que existem dois tipos de implícitos: aqueles que têm origem no componente linguístico, ou seja, na significação das frases, e aqueles que têm origem na enunciação, que são os subentendidos. Essa é a primeira característica dessa segunda classe, o fato de ser resultado de um efeito da enunciação.

As colocações de Ducrot (1977) acompanham aquelas presentes em Ducrot (1987b) e parecem apresentar com muita clareza a natureza dos subentendidos. Para o autor, "o implícito não deve ser procurado no nível do enunciado [frase], 
como um prolongamento do nível explícito, mas num nível mais profundo, como uma condição de existência do ato de enunciação [enunciado]" (DUCROT, 1977, p. 07).

Pelo fato de não se situar no nível explícito do enunciado, mas constituir-se do resultado do raciocínio do ouvinte, o subentendido é descrito como à margem do sentido literal, como não pertencente à significação linguística, podendo o locutor, a qualquer momento, negar a responsabilidade pelo subentendido, apelando para o dito em seu enunciado.

Voltemos ao exemplo (2) Pedro gosta de carros importados, no qual há a presença do conteúdo evocado (2') Pedro gosta pouco (ou menos) de carros nacionais, atestado pela lei de economia que, lembramos, supõe serem necessárias todas as "informações" que o locutor disponibiliza no enunciado. No entanto, esse conteúdo não pode ser classificado como um pressuposto, pois não resiste às transformações sintáticas operadas pela negação e pela interrogação, exemplificadas por (2a) É falso que Pedro gosta de carros importados e por (2b) É verdadeiro que Pedro gosta de carros importados?.

O locutor do enunciado pode negar também ter tido a intenção de incorporar o sentido $\left(2^{\prime}\right)$ ao seu enunciado, dizendo (2c) Pedro gosta de carros importados e até mesmo de carros nacionais, pois tal encadeamento é totalmente lícito e previsto na orientação argumentativa de (2), sobre a qual o locutor pode apoiar-se para negar o subentendido (2'). Assim, os sentidos subentendidos parecem não estar prefigurados na significação da frase que o enunciado realiza e a partir do qual são derivados, mas parecem ter-lhe sido acrescentados pela interpretação do ouvinte. O implícito subentendido não é encontrado, mas reconstruído, e constitui-se puramente como um fato de fala (DUCROT, 1977).

O locutor beneficia-se, portanto, da eficácia da sua enunciação para comunicar determinado sentido que não poderia (ou não teria o direito) de dizer abertamente, deixando para o ouvinte concluí-lo. Por isso, tem-se a impressão de que a compreensão dos subentendidos acontece em um momento posterior ao momento da enunciação (por oposição aos pressupostos, que se situariam em um momento passado do conhecimento tanto do locutor quando do interlocutor), que surgiriam após a reflexão do ouvinte a respeito das circunstâncias da mensagem que o locutor lhe transmite. $\mathrm{O}$ 
enunciado (8) Pedro concluiu seu doutorado em apenas dois anos, por exemplo, pode ser usado pelo locutor para deixar subentendido ao destinatário $\left(8^{\prime}\right)$ Gostaria que você concluísse seu doutorado antes do prazo, caso o locutor-orientador queira dar a entender que gostaria que seu aluno concluísse seu doutorado em breve; ou pode insinuar ao destinatário (8") É possível concluir um doutorado em dois anos, caso queira motivá-lo a concluir seu doutorado antes do prazo final.

Dessa forma, o locutor pode sugerir a seu destinatário determinado sentido, sem, contudo, admitir a responsabilidade por tê-lo dito. O locutor beneficia-se do conteúdo linguístico que enuncia, pois, a partir dele, comunica ao destinatário da mensagem um conteúdo derivado, que não encontra fundamento na significação. $O$ interlocutor chega ao subentendido pela análise dos enunciados e das suas circunstâncias de enunciação, questionando: Por que o locutor disse o que disse?

Contrariamente à pressuposição, os subentendidos não resistem à ação transformadora da negação e da interrogação, cuja explicação encontra-se no fato de não estarem fundamentados na significação das palavras componentes do enunciado, sobre as quais incidem essas transformações sintáticas, mas por serem um efeito da enunciação, sobre a qual tais transformações não têm o poder de operar. Além disso, Ducrot (1987c) afirma que o critério do encadeamento não permite que se dê continuidade a um discurso encadeando outro enunciado a partir de seus pressupostos.

Nós concluímos, quanto ao subentendido, que a oposição à pressuposição se mantém também neste critério, pois é possível encadear a sequência do discurso a partir de seus subentendidos, conforme (8a). O locutor-orientador, através de (8) Pedro concluiu seu doutorado em apenas dois anos, subentende (8') Gostaria que você concluísse seu doutorado antes do prazo, ao que Pedro poderia responder (8a) Eu não concluirei meu doutorado antes do fim do prazo, pois preciso realizar uma longa coleta de dados. O locutor-orientador poderia negar o subentendido, afirmando (8b) Pedro concluiu seu doutorado precocemente pois foi aprovado em um concurso público.

Os subentendidos voltam a ser mencionados muitos anos mais tarde, desta vez em um trabalho de Carel (2011), no qual há apenas a menção a eles para opô-los, mais uma vez, 
aos pressupostos. Nesse trabalho, Carel segue as diretrizes apontadas em Carel e Ducrot (2008), no qual propunham uma mudança radical em relação à descrição e à explicação dos pressupostos. Essa mudança diz respeito a dois aspectos, especialmente: à disjunção do sentido do enunciado em dois conteúdos independentes, o posto e o pressuposto, e à descrição polifônica realizada, pela qual cada um dos conteúdos seria de responsabilidade de um enunciador diferente, com os quais o locutor tomaria determinadas atitudes - concordar com o enunciador que sustenta o conteúdo pressuposto e assumir o enunciador responsável pelo conteúdo posto, tal como exposto acima.

Assim, as mudanças na análise dos subentendidos expressas no trabalho de Carel (2011) com relação a Ducrot (1987c) dizem respeito apenas a reformulações da Teoria da Argumentação Polifônica, com a introdução dos modos e pessoas. Nesse cenário, o exemplo de subentendido dado pela autora vem ao encontro da demonstração daquilo que não é considerado como um pressuposto. Para ela, os fenômenos subentendidos não podem jamais ser classificados como polifônicos.

Da mesma maneira que os enunciados com pressupostos do tipo (3) Pedro parou de fumar comunicam um conteúdo implícito - (3') Pedro fumava antes -, o enunciado (9) Alguns livros foram doados à biblioteca também comunica o conteúdo implícito (9') Alguns livros não foram doados à biblioteca. No entanto, diferentemente do que acontece com (3'), o implícito $\left(9^{\prime}\right)$ não resiste à transformação operada pela interrogação (9a) Alguns livros foram doados à biblioteca?, o que não o caracteriza como pressuposto. Além disso, o locutor pode negar ter comunicado esse conteúdo, dizendo (9b) Alguns livros foram doados à biblioteca, e até mesmo todos.

\section{Algumas reflexões sobre as noções apresentadas}

Em seu texto de (1987c), Ducrot reexamina a tese que afirma a oposição pressuposto-subentendido pela pertinência dos pressupostos à frase e dos subentendidos à enunciação. $\mathrm{O}$ objetivo desse reexame é justamente desfazer a oposição criada em Ducrot (1987b), pela qual pressupostos e subentendidos teriam origem em estratos diferentes da atividade linguística 
- um estando ligado estritamente ao componente linguístico, e o outro, ao componente retórico. Conforme já vimos anteriormente, Ducrot apresenta três justificativas para inscrever o pressuposto na significação das frases. No entanto, a mudança de perspectiva com relação à pressuposição atinge apenas de modo indireto a descrição dos subentendidos, que continuam a fazer parte dos efeitos da enunciação, pois, sendo observáveis em apenas algumas ocorrências da frase, não se encontram nela marcados. "Para que um enunciado $\mathrm{E}$ subentenda $X, X$ deve aparecer com uma explicação da sua enunciação" (DUCROT, 1987c, p. 32).

O que muda de modo mais visível é a relação pressupostosubentendido: para Ducrot (1987c), a pressuposição é um ato (ilocutório) em si, enquanto o que se subentende é um ato (subentende-se uma afirmação, um conselho, uma dúvida ou até mesmo um pressuposto como no exemplo (4e) e (4f)). É uma diferença bastante sutil, mas que toca diretamente naquilo que os diferenciava, pois subentendido e pressuposto deixam de estar em relação de oposição, uma vez que já não pertencem mais ao mesmo nível - só é possível opor coisas que de algum modo aparecem interligadas.

O pressuposto, para o autor, é parte integrante do sentido dos enunciados, pois não há como enunciar uma frase com pressupostos sem denunciar sua presença: funciona como uma imagem da enunciação, é imposto ao ouvinte. Já no que tange aos subentendidos, é perfeitamente possível que o interlocutor encadeie a continuidade do discurso a ele. $\mathrm{O}$ interlocutor não é constrangido a aceitar os subentendidos, eles apenas dizem respeito ao modo pelo qual se deve interpretar o discurso do locutor, o processo ao final do qual o alocutário resgata a imagem que o locutor quer dar-lhe de sua fala. $\mathrm{O}$ uso de um enunciado com pressupostos já impõe ao destinatário a imagem do discurso do locutor, enquanto o subentendido é o resultado ao qual o interlocutor chega a partir da imagem que o locutor deu ao seu discurso, como um efeito secundário deste.

Um ponto em comum, entretanto, é possível apontar: tanto em relação aos pressupostos quanto em relação aos subentendidos, é dada a possibilidade ao locutor de se retirar de sua fala. No primeiro caso, da pressuposição, pela impossibilidade de o interlocutor dar continuidade ao discurso encadeando sua fala aos pressupostos (numa situação de 
discurso ideal). Sobre os subentendidos, o locutor poderá sempre apelar ao "sentido literal" de seu enunciado para negar que teve a intenção de comunicar este ou aquele conteúdo.

Conforme definição, o subentendido é resultado de um processo realizado pelo interlocutor, como resposta a perguntas do tipo: Por que o locutor disse o que disse? ou Por que o locutor falou desse modo? "O locutor apresenta sua fala como um enigma que o destinatário deve resolver. O sentido, que é sempre, para mim, um retrato da enunciação, é um retrato cuja responsabilidade L deixa ao destinatário." (DUCROT, 1987e, p. 42). Nesse caso, portanto, é possível que o locutor se exima da responsabilidade que teria pelos subentendidos já que esse conteúdo pode ser negado apelando àquilo que os autores denominam de "sentido literal", que exclui, portanto, os efeitos do uso da língua, nos quais se situam os subentendidos.

\section{REFERÊNCIAS}

ANSCOMBRE, Jean-Claude; DUCROT, Oswald. L'Argumentation dans la langue. Belgique: Mardaga, 1983.

CAREL, Marion. Vers une formalisation de la théorie de l'argumentation dans la langue. 1992. Tese (Doutorado) - École des Hautes Études en Sciences Sociales (EHESS), Paris.

CAREL, Marion; DUCROT, Oswald. La semántica argumentativa: una introducción a la Teoría de los Bloques Semánticos. Buenos Aires: Colihue, 2005.

Descrição argumentativa e descrição polifônica: o caso da negação. In.: Letras de Hoje. Porto Alegre, v.43, n. 1, p. 7-18. Jan/mar 2008.

CAREL, Marion. La poly phonie linguistique. In: Transposition; musique et sciences sociales. Paris: EHESS, n. 1, 2011. <http:// transposition-revue.org/les-numeros/polyphonie-et-societe/ article/la-polyphonie-linguistique>.

DUCROT, Oswald. Princípios de semântica linguística: dizer e não dizer (1972). São Paulo: Cultrix, 1977.

DUCROT, Oswald. Esboço de uma teoria polifônica da enunciação. In.: DUCROT, Oswald. O dizer e o dito (1984). Campinas: Pontes, 1987a. 
DUCROT, Oswald. Pressupostos e subentendidos: a hipótese de uma semântica linguística (1969). In.: DUCROT, Oswald. O dizer e o dito (1984). Campinas: Pontes, 1987b.

Pressupostos e subentendidos (reexame) (1977). In.: DUCROT, Oswald. O dizer e o dito (1984). Campinas: Pontes, 1987c.

. Nota sobre a pressuposição e o sentido literal (posfácio). In.: HENRY, Paul. A ferramenta imperfeita (1977). Campinas: Editora da Unicamp, 1992.

FILLMORE, Charles J. ; LANGENDOEN, D. Terence. Studies in linguistic semantics. New York: Holt, Rinehart and Winston, 1971, p. 44-52.

FREGE, Gottlob. Lógica e filosofia da linguagem. São Paulo: Cultrix, 1978.

SELLARS, Wilfrid. Presupposing. The Philosophical Review. Vol. 63, No. 2. (Apr.,1954), pp. 197-215.

STRAWSON, Peter Frederick (1950). Sobre referir. In: Os Pensadores. São Paulo: Abril Cultural, v.52, p. 261- 280. 


\section{Abstract \\ Presupposition and implicit according to Argumentation in Language Theory}

This study aims to conduct a diachronic study of the presupposition and implicit concepts according to Argumentation in Language Theory (ALT). Initially developed by Oswald Ducrot and JeanClaude Anscombre and, more recently, by Oswald Ducrot and Marion Carel, the ALT went through reformulations which kept it faithful to its basic presupposed, that is, the argumentation is within the language. Those reformulations, such as exclusion of pragmatic elements and the non-acceptance of topoi as constructive of meaning, impacted in the explanation of some linguistic phenomena, among which we situate those that we are analyzing. To carry out our aim, it was read some theoretical texts which deal with the issue in order to retrace the path that presents how the presupposition and implicit are understood in each one of the phases.

Key words: Presupposition. Implicit. Meaning. 